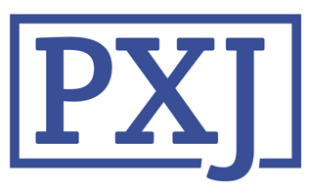

Patient Experience Journal

Volume 4

Issue 2 Special Issue: Patient Involvement

Article 4

2017

\title{
Lack of patient involvement in care decisions and not receiving written discharge instructions are associated with unplanned readmissions up to one year
}

Kyle A. Kemp

University of Calgary

Hude Quan

University of Calgary

Maria J. Santana

University of Calgary

Follow this and additional works at: https://pxjournal.org/journal

Part of the Health and Medical Administration Commons, Health Policy Commons, Health Services Administration Commons, and the Health Services Research Commons

\section{Recommended Citation}

Kemp KA, Quan H, Santana MJ. Lack of patient involvement in care decisions and not receiving written discharge instructions are associated with unplanned readmissions up to one year. Patient Experience Journal. 2017; 4(2):13-22. doi: 10.35680/2372-0247.1205.

This Research is brought to you for free and open access by Patient Experience Journal. It has been accepted for inclusion in Patient Experience Journal by an authorized editor of Patient Experience Journal. 


\section{Lack of patient involvement in care decisions and not receiving written discharge instructions are associated with unplanned readmissions up to one year}

\section{Cover Page Footnote}

The authors wish to thank the patients who took the time to complete the inpatient experiences survey. We also acknowledge the team of Health Research Interviewers from Primary Data Support, Analytics (DIMR); Alberta Health Services, who administered the surveys. 


\title{
Lack of patient involvement in care decisions and not receiving written discharge instructions are associated with unplanned readmissions up to one year
}

Kyle A. Kemp, University of Calgary, kekemp@ucalgary.ca

Hude Quan, University of Calgary, hquan@ucalgary.ca

Maria J. Santana, University of Calgary,mjsantan@ucalgary.ca

\begin{abstract}
This retrospective, cross-sectional study examined the relationship between aspects of inpatient communication and discharge instructions and unplanned, all-cause readmissions using individual-level data up to one-year post-discharge. Patients completed the Hospital Consumer Assessment of Healthcare Providers and Systems (HCAHPS) telephone survey within 6 weeks of hospital discharge in Alberta, Canada. Survey data were linked to corresponding inpatient records. Independent variables included selected demographic characteristics, clinical variables, and five survey questions: a) patient involvement in care decisions, b) receiving written information at discharge, c) understanding the purpose of taking medications, d) understanding responsibility for one's health, and e) discussing help needed when returning home. From April 2011 to March 2014, 24,869 patients with a mean age of 52.8 \pm 19.8 years (range=18-100) were included. $18.6 \%$ of patients $(n=4,821)$ experienced an unplanned hospital readmission within 43 to 365 days postdischarge. In adjusted, logistic regression models, patients who felt they were not involved in care decisions were more likely to be readmitted ( $\mathrm{OR}=1.34$; 95\% CI: 1.17-1.53), as were patients who reported not receiving written information about signs and symptoms to watch out for post-discharge (OR=1.24; $95 \% \mathrm{CI}$ : 1.15-1.35). Odds of readmission did not differ according to understanding of medications, understanding responsibility for one's health, or discussion of help needed when returning home. This study provides objective data, showing that specific hospital actions are associated with unplanned readmissions. It is an example of how patient-reported measures may be linked to administrative data to drive quality improvement initiatives.
\end{abstract}

\section{Keywords}

Patient experience, unplanned readmissions, HCAHPS, communication, discharge

\section{Note}

The authors wish to thank the patients who took the time to complete the inpatient experiences survey. We also acknowledge the team of Health Research Interviewers from Primary Data Support, Analytics (DIMR); Alberta Health Services, who administered the surveys.

\section{Introduction}

Patient experience is one of the three components of the Institute for Healthcare Improvement's (IHI) Triple Aim Framework for optimizing health system performance. ${ }^{1}$ Under the auspices of the Affordable Care Act ${ }^{2}$, the Hospital Consumer Assessment of Healthcare Providers and Systems (HCAHPS) survey has emerged as the gold standard for measuring patient experience. Having this appropriate gold standard is essential when making meaningful comparisons between hospitals and health systems. As a measure of healthcare quality, HCAHPS results have been publicly reported in the United States since 2008. Since 2013, they have also been considered as part of the Value-Based Purchasing (VBP) program for hospital reimbursement. ${ }^{3}$
Another established measure of healthcare quality is unplanned hospital readmissions. Regardless of the timeframe for readmission, (e.g. 7, 30, 90, 365-days postdischarge), these events represent significant costs to healthcare systems worldwide. A 2009 article in the New England Journal of Medicine showed that approximately $20 \%$ of U.S. Medicare beneficiaries were readmitted within 30-days; representing $\$ 15$ billion in annual excess costs. ${ }^{4}$ Similarly, a report published by the Canadian Institute for Health Information (CIHI) demonstrated that the 30-day all-cause readmission rate among Canadian hospitals was $8.5 \%$, while the average cost of each of these readmissions was estimated to be $\$ 9,805.5$ Although there are many factors at play, readmitted patients have been found to be older $^{6}$ and to have more complications and 
comorbidities. ${ }^{7,8}$ Even if many of these contributing factors may be non-modifiable, unplanned readmissions are largely seen as preventable, with the CIHI report estimating that $9-59 \%$ of all-cause readmissions in Canada may be prevented. This is also reflected in the United States, where since 2012, the Centers for Medicare and Medicaid Services' (CMS) Readmission Reductions Program (HRRP) has adjusted hospital payments based on readmissions. ${ }^{9}$

Two notable studies have examined the relationship between patient experience and unplanned readmissions. The first of these was conducted in 2011 by Boulding and colleagues, who demonstrated that higher ratings of hospital satisfaction were associated with lower 30-day readmission rates. ${ }^{10}$ Despite this positive finding, one study limitation was that it used hospital-level satisfaction and readmission data, which were publicly available. By not using individual-level data, the findings from the study may be prone to the ecological fallacy; whereby inferences deduced at a group-level may not apply to all individuals which comprise that group. ${ }^{11}$ Simply said, some patients with high satisfaction may have been readmitted. Likewise, a number of patients with low satisfaction ratings may not have returned to hospital. A secondary limitation of the study lies in the readmission period used (e.g. 30 days post-discharge) and its relation to the HCAHPS survey eligibility period (e.g. 2 to 42 days post-discharge). Although 30-day readmission rates are used in the CMS' HRRP, we argue that it is possible that patients could have completed the HCAHPS survey after being readmitted to hospital - an occurrence which may have influenced the respondents' answers. Similarly, asking respondents to recall aspects of their care during the survey may have elicited a "red flag" on the patient's part; possibly prompting a return to hospital. Thus, we advocate that when using the HCAHPS survey to measure patient experience, it may be prudent to look at longer-term readmissions (e.g. beyond the 42-day HCAHPS eligibility period) to limit potential confounding. Previous research has looked at longer readmissions as a measure of effectiveness of interventions while in-hospital, particularly those tailored around improving medication compliance, discharge planning, and managing one's condition in the community. ${ }^{12-14}$

In the second study, conducted by Hachem and colleagues in $2014^{15}$, the authors addressed a limitation of the Boulding study by using individual-level data. The authors examined the relationship between specific aspects of patient experience (e.g. nurse communication, physician communication, discharge communication), and unplanned readmissions. These aspects were selected by the authors, as previous studies showed that survey questions pertaining to communication had the strongest association with overall satisfaction. ${ }^{10,16}$ These results have also been consistently replicated in HCAHPS U.S.-public reporting ${ }^{17}$ and in a preliminary Canadian investigation by our group. ${ }^{18}$ The previous limitation regarding the readmission period (e.g. 30 days), however, remained present in the study by Hachem and colleagues.

Based upon this, our goal was to examine the potential associations between patient-reported aspects of communication and discharge care with unplanned readmissions up to one year post-discharge. Specific survey questions pertained to patient involvement in care decisions, patients receiving written information at discharge, patients understanding the purpose of taking medications, patients understanding their responsibility in managing their health, and patients discussing help needed when returning home. Unlike previous studies, however, we examined readmissions over a longer follow-up period (43-365 days post-discharge). Our hypothesis was that a better patient experience score on each item would be associated with lower readmission rate. The study links individual-level patient experience surveys and clinical data in a Canadian context - something which has not been routinely done to date.

\section{Methods}

This study was a retrospective, cross-sectional study of patients $(n=24,869)$ who were discharged from hospitals between April 2011 and March 2014, and who completed the HCAHPS telephone survey within 6 weeks of discharge. Respondents were a random sample of adults discharged from 93 hospitals in Alberta, Canada. In the province of Alberta, all hospital care is provided by a single healthcare organization; Alberta Health Services (AHS). As per the HCAHPS inclusion criteria ${ }^{19}$, patients under 18 years of age, who had an inpatient stay of less than 24 hours, who died during hospital stay, who were admitted to a psychiatric unit, who had a psychiatric physician consultation, or who had day surgery or ambulatory procedures were excluded. For compassionate reasons, AHS also excluded any visits relating to still births, dilation and curettage (D\&C) procedures, or linked to a newborn with length of stay greater than 6 days (e.g. complication/neonatal intensive care unit stay). ${ }^{20}$

A modified version of the HCAHPS survey was used. The survey was comprised of 51 questions, including the 32 core HCAHPS ones. The remaining 19 questions addressed organization-specific policies and procedures such as patient concerns, pharmacy care, and patient education (Table 1). Each survey required 15 to 20 minutes to complete. Interviewers followed a standard script with a list of prompts and frequently asked questions and captured data via computer-assisted telephone interview (CATI) software (Voxco; Montreal, Canada). At the conclusion of each survey, any patient with a concern, complaint, or compliment about the services they received were provided with contact 
Table 1 Additional questions not part of core H-CAHPS survey $(n=19)$

Question Description

Nurse follow-up

Nurse overall rating

Doctor follow-up

Doctor overall rating

Involvement in care decisions

Family/friend inclusion

Health team coordination

Famiy/friend visiting

Meeting with pharmacist

Pharmacist overall rating

Patient role in safety

Overall quality of care

Healthcare complaint

Nature of complaint

Complaint action

Complaint welcomed

Complaint taken seriously

Complaint satisfaction

Born in Canada

\section{Question Wording}

During this hospital stay, how often did nurses follow up on your concerns and observations?

We want to know your overall rating of the care you received from nurses during this hospital stay. Using any number from 0 to 10 , where 0 is the worst possible nursing care and 10 is the best possible nursing care, what number would you give the care that you received from all the nurses who treated you?

During this hospital stay, how often did doctors follow up on your concerns and observations?

We want to know your overall rating of the care you received from doctors during this hospital stay. Using any number from 0 to 10 , where 0 is the worst possible care and 10 is the best possible care, what number would you give the care that you received from all the doctors who treated you?

During your hospital stay, did you have enough involvement in decisions about your treatment?

During your hospital stay, how much did hospital staff include your family or someone close to you in decisions about your care?

During this hospital stay, how would you describe how well all of the health care professionals coordinated their efforts to serve your needs?

Were your family or visitors welcomed at the hospital at the times that you wanted them to be there?

During your hospital stay, did you meet with a pharmacist?

We want to know your rating of the overall contact you had with the pharmacists during your hospital stay. Using any number from 0 to 10 , where 0 is the worst possible contact and 10 is the best possible contact, what number would you give the contact you had with the pharmacists who treated you?

During this hospital stay, did you get information in writing and/or verbally about your role in safety practices? For example, cleaning your hands and knowing your own medication.

How would you rate the quality of care you most recently received at the hospital?

Did you have a complaint about any of the health care services you received during this hospital stay?

What is the nature of this complaint? (open-ended question)

Which of the following best describes what you have done about your complaint?

Did you feel your complaint was welcome?

Did you feel your complaint was taken seriously?

To what extent were you satisfied or dissatisfied with how your complaint was handled and addressed?

Were you born in Canada? information for the organization's Patient Relations department.
Ethical approval for the study was obtained from the Conjoint Health Research Ethics Board (CHREB) at the University of Calgary (file number REB14-2338). A data sharing agreement was signed between the research team 
and AHS. A waiver of consent was granted by the ethics board due to retrospective nature of the study. As part of the telephone survey protocol, prospective respondents were informed of that their data could be used for quality assurance and/or research purposes. Completed surveys were linked to corresponding electronic discharge records, as documented in the Discharge Abstract Database

(DAD). ${ }^{21}$ Linkage was performed using exact matches for three data points; personal health number (PHN), facility code, and discharge date.

\section{Study variables}

The dependent study variable was all-cause, unplanned readmission to hospital (yes vs. no) within 43-365 days of discharge. This follow-up period was selected in order to account for the HCAHPS survey eligibility period (e.g. 242 days post discharge). Only unplanned readmissions, as denoted by a DAD record with an admission category of "urgent" (ADMITCAT $=\mathrm{U})^{22}$ were included.

Independent predictors included in the analyses were five survey questions pertaining to communication and discharge care, as well as a collection of demographic, clinical, and other survey variables. The five survey questions asked about patient involvement in their care decisions, patients receiving written information at hospital discharge, patients understanding the purpose of taking all of their medications, patients understanding their responsibility in managing their own health, and whether patients discussed any help that they would need when returning home. Each of these were dichotomized according to the HCAHPS "top box" methodology, where "top box" represented the best possible option for each question. ${ }^{23}$ From a quality improvement perspective, these "top box" responses are what hospitals/healthcare organizations strive to achieve. The five questions, their complete wording (as read to respondents), and all possible answer choices are provided in Table 2. Demographic variables included sex, age group (in years) at hospital discharge (18 to 49; 50 to 64; 65 and older), and education level (high school or less; greater than high school). Clinical variables included for analysis were inpatient hospitalization over the previous year (yes/no) and length of index hospital stay (3 days or less; more than 3 days). From the survey, the patient's overall rating of their care (score from 0 [worst] to 10 [best]) was

Table 2. Questions pertaining to communication and discharge care

\begin{tabular}{|c|c|c|}
\hline Survey Question & Question Text & Answer Choices \\
\hline $\begin{array}{l}\text { Patient involvement in their } \\
\text { care decisions }\end{array}$ & $\begin{array}{l}\text { During your hospital stay, did you have enough } \\
\text { involvement in decisions about your treatment? }\end{array}$ & $\begin{array}{l}\text { Yes, definitely* } \\
\text { Yes, somewhat* } \\
\text { No }\end{array}$ \\
\hline $\begin{array}{l}\text { Receiving written information } \\
\text { at hospital discharge }\end{array}$ & $\begin{array}{l}\text { During this hospital stay, did you get information, in } \\
\text { writing, about what symptoms or health problems to } \\
\text { look out for, after you left the hospital? }\end{array}$ & $\begin{array}{l}\mathrm{Yes}^{*} \\
\mathrm{No}\end{array}$ \\
\hline $\begin{array}{l}\text { Understanding purpose of } \\
\text { taking all medications }\end{array}$ & $\begin{array}{l}\text { Please indicate how much you agree or disagree with the } \\
\text { following statements. When you left the hospital, you } \\
\text { clearly understood the purpose for taking each of your } \\
\text { medications. }\end{array}$ & $\begin{array}{l}\text { Strongly agree* } \\
\text { Agree* } \\
\text { Disagree } \\
\text { Strongly disagree }\end{array}$ \\
\hline $\begin{array}{l}\text { Understanding responsibility in } \\
\text { managing own health }\end{array}$ & $\begin{array}{l}\text { Please indicate how much you agree or disagree with the } \\
\text { following statements. When you left the hospital, you } \\
\text { had a good understanding of the things that you were } \\
\text { responsible for in managing your health. }\end{array}$ & $\begin{array}{l}\text { Strongly agree* } \\
\text { Agree* } \\
\text { Disagree } \\
\text { Strongly disagree }\end{array}$ \\
\hline $\begin{array}{l}\text { Discussion of help needed } \\
\text { when returning home }\end{array}$ & $\begin{array}{l}\text { During your hospital stay, did doctors, nurses or other } \\
\text { hospital staff talk with you about whether you would } \\
\text { have the help you needed when you left the hospital? }\end{array}$ & $\begin{array}{l}\mathrm{Yes}^{*} \\
\text { No }\end{array}$ \\
\hline
\end{tabular}


considered. This was dichotomized as per the HCAHPS "top box" analysis plan, where responses of 9 or 10 out of 10 were considered to be in the "top box". ${ }^{23}$ Patients' ratings of their physical and mental health (excellent or very good; good; fair or poor) were also included in our analysis.

\section{Analysis}

Characteristics of the study sample were reported using descriptive statistics. Logistic regression was used to assess the relation between each of the five communication and discharge care survey questions and unplanned readmissions within 43-365 days post-discharge. Although not a goal of the paper, we also reported the results for readmissions within 30 days; allowing for comparisons to previous literature. Each adjusted model controlled for all of the aforementioned demographic, clinical and survey items. When applicable, corresponding odds ratios and 95\% confidence intervals were reported. Any confidence interval which did not contain the 1.0 value was considered statistically significant. All analyses were performed using Statistical Analysis System (SAS) version 9.3 (SAS Institute; Cary, NC).

\section{Results}

Characteristics of the study sample are provided in Table 3. The mean age of the cohort was $52.8 \pm 19.8$ years

Table 3. Demographics/clinical characteristics of the sample $(n=24,869)$

\begin{tabular}{|c|c|c|}
\hline Variable & n & $\%$ \\
\hline \multicolumn{3}{|l|}{$\underline{\text { Sex }}$} \\
\hline Male & 8,605 & 34.6 \\
\hline Female & 16,264 & 65.4 \\
\hline \multicolumn{3}{|l|}{ Age Group (in years) } \\
\hline Under 50 & 10,669 & 42.9 \\
\hline 50 to 64 & 6,070 & 24.4 \\
\hline 65 and older & 8,130 & 32.7 \\
\hline \multicolumn{3}{|l|}{ Education Level } \\
\hline High school or less & 11,314 & 45.5 \\
\hline Greater than high school & 13,555 & 54.5 \\
\hline \multicolumn{3}{|l|}{ Inpatient Hospitalization in Year Prior } \\
\hline Yes & 7,516 & 30.2 \\
\hline No & 17,353 & 69.8 \\
\hline \multicolumn{3}{|l|}{ Length of Hospital Stay (days) } \\
\hline 3 or less & 14,811 & 59.6 \\
\hline More than 3 & 10,058 & 40.4 \\
\hline \multicolumn{3}{|l|}{ Overall Rating of Care } \\
\hline 9 or 10 (out of $10-$ Best Possible) & 15,319 & 61.6 \\
\hline 0 (Worst Possible) to 8 & 9,550 & 38.4 \\
\hline \multicolumn{3}{|l|}{ Self-Rating of Physical Health } \\
\hline Excellent or very good & 11,684 & 47.0 \\
\hline Good & 7,426 & 29.8 \\
\hline Fair or poor & 5,759 & 23.2 \\
\hline \multicolumn{3}{|l|}{ Self-Rating of Mental Health } \\
\hline Excellent or very good & 16,129 & 64.8 \\
\hline Good & 6,266 & 25.2 \\
\hline Fair or poor & 2,474 & 9.9 \\
\hline \multicolumn{3}{|l|}{ Percent of Cohort Readmitted within: } \\
\hline 7 Days & 391 & 1.6 \\
\hline 30 Days & 1,034 & 4.2 \\
\hline 43 Days to 1 Year & 4,621 & 18.6 \\
\hline
\end{tabular}


(range $=18$ to 100$) .65 .4 \%(n=16,264)$ of respondents were female, and $54.5 \%(n=13,555)$ were educated beyond a high school level. The mean length of hospital stay was 5.2 days (median=3.0; range $=1$ to 329). A "top-box" rating for overall care (score of 9 or 10 out of 10) was provided by $61.6 \%(n=15,319)$ of the cohort. Patients had more favorable ratings of their mental health than their physical health $(64.8 \%$ versus $47.0 \%$ reporting excellent or very good). Just over $30 \%$ of the cohort had been hospitalized during the previous year, and $18.6 \%$ of the cohort $(n=4,621)$ had at least one unplanned readmission in the 43-365 day period following index hospitalization. The mean length of time from discharge to first readmission was $151.3 \pm 111.54$ days (median=137).

Table 4 shows the descriptive results for the five survey questions pertaining to communication and discharge care. A majority of patients reported "top box" ratings to each of these questions. Percentages of patients with "top-box" responses ranged from $96.7 \%$ (understanding purpose of taking all medications), to $71.1 \%$ (receiving written information at discharge).

Table 5 (end of article) contains the results of the unadjusted and adjusted logistic regression analyses. Not having a "top box" response to each the five questions pertaining to communication and discharge care was independently associated with higher odds of readmission up to one year. The highest odds ratio observed was for not receiving written information at discharge $(\mathrm{OR}=1.96$, 95\%CI: 1.82-2.10). Not having a "top box" overall rating of care was also independently associated with unplanned readmission $(\mathrm{OR}=1.09,95 \% \mathrm{CI}$ : 1.02-1.17). When controlling for sex, age group, education level, length of stay, hospitalization in previous year, overall rating of care, self-rated physical health, and self-rated mental health, patients not being involved in care decisions $(\mathrm{OR}=1.34$, 95\% CI: 1.17-1.53) and not receiving written information at discharge $(\mathrm{OR}=1.24,95 \% \mathrm{CI}$ : 1.15-1.35) remained significant. When controlling for all other factors, not having a "top box" overall rating of care also remained significant (OR=1.10, 95\%CI: 1.02-1.18). Additionally, there was evidence of a cumulative effect: When compared with respondents who reported being involved in care and receiving written discharge information, those who reported "no" to both questions had a much higher odds of readmission (adjusted OR=1.54, 95\%CI: 1.29-1.83). For the 30-day results, all five of the questions examined were significant, both in crude and adjusted regression models.

Table 4. Responses to survey questions pertaining to communication and discharge care $(n=24,869)$

\begin{tabular}{lrr} 
Variable & $\mathbf{n}$ & $\%$ \\
Patient Involvement in Care Decisions & & \\
\hline Yes (as much as desired or somewhat) & 21,884 & 93.3 \\
No (wanted to be more involved) & 1,575 & 6.7 \\
No response/not applicable & 1,410 & ---- \\
Received Written Information at Discharge & & \\
Yes & 16,155 & 71.1 \\
No & 6,561 & 28.9 \\
No response/not applicable & 2,153 & ---- \\
& & \\
Understood Purpose of Taking Medications & & \\
Agree & 22,383 & 96.7 \\
Disagree & 754 & 3.3 \\
No response/not applicable & 1,732 & ---- \\
& & \\
Understood Responsibility for Own Health & 23,457 & 95.4 \\
Agree & 1,125 & 4.6 \\
Disagree & 287 & ----- \\
No response/not applicable & & \\
$\quad$ Discussed Help Needed when Returning Home & & \\
Yes & 18,290 & 82.9 \\
No & 3,761 & 17.1 \\
No response/not applicable & 2,818 & ----
\end{tabular}




\section{Discussion}

We found that independently, all five aspects of communication and discharge care which we examined were associated with all-cause, unplanned readmissions from 43-365 days post-discharge. These aspects were patient involvement in their care decisions, patients receiving written information at hospital discharge, patients understanding the purpose of taking all of their medications, patients understanding their responsibility in managing their own health, and whether patients discussed any help that they would need when returning home. Once controlling for a variety of demographic and clinical factors, as well as one's overall rating of care, only level of involvement in care decisions and receiving written discharge information remained statistically significant. Specifically, patients who reported always not being involved in their care decisions had 34\% higher odds of re-admission, compared with those who reported some degree of involvement. Additionally, patients who reported that they did not receive written information about what symptoms or health problems to look out for after leaving the hospital had $24 \%$ higher odds of readmission. Interestingly, not being involved in one's care and not receiving written discharge information had a cumulative effect; with those respondents having a 54\% higher odds of readmission, when compared with respondents who reported being involved in their care and having received written discharge information.

Our findings are for the most part, concurrent with previous studies which have used hospital-level ${ }^{10}$ and individual-leve ${ }^{15}$ data to examine readmissions over the first 30 days following discharge. One finding which was not replicated at the one-year mark, was the finding by Hachem and colleagues, who showed a link between discussing help needed after hospital discharge and readmissions. ${ }^{15}$ We reported a null result for this relationship.

In conjunction with previous literature, our results reinforce that linking HCAHPS surveys to administrative data for quality improvement purposes is both feasible and useful. As HCAHPS is a validated, accepted gold-standard for measuring patient experience, one may use the data to make meaningful comparisons across hospitals and healthcare organizations. However, we advocate that, whenever possible, such linkages should be made at the individual-level. There are many opportunities for future use of inpatient experience data. For example, communication between clinicians and patients plays a fundamental role in patient-centered care (PCC), which is considered to be one of the six key elements of highquality care. ${ }^{24}$ Although patient experience and unplanned readmissions are established measures of healthcare quality, we propose that examining these independently from one-and-other may only provide a portion of the picture. For quality improvement purposes, we advocate that examining how specific elements of patient experience (e.g. communication with staff, discharge planning, etc.) may correlate with unplanned readmissions could provide greater value. These proposed data linkages may lead to a list of items (e.g. providing written discharge instructions, providing a written list of medications to be reviewed) for clinicians to action and complete with patients and family members. In doing so, the impact of said items upon healthcare utilization (e.g. readmissions, emergency department visits) can be easily measured; providing objective data for physicians, hospital administrators, and researchers. The data generated can also serve as a valuable patient teaching and education tool. For example, a draft checklist for patients may help prompt points for discussion immediately prior to discharge. A systematic review by Gleeson and colleagues provides data regarding approaches to using patient experience data for quality improvement purposes. ${ }^{25}$

The present study has several strengths. To our knowledge, it is the first one to examine the potential relationship between targeted elements of patient experience (as measured via the HCAHPS survey) and readmissions over the longer term. It uses individual-level data linkage, which eliminates any possibility of ecological fallacy. Secondly, using inpatient records (as provided by the $\mathrm{DAD}$ ), we were able to consider only urgent readmissions in our analysis plan. By not considering elective (e.g. scheduled/planned) readmissions, we were able to examine only readmissions which may be considered preventable. An additional strength lies within the quality and coverage of our survey and administrative data. All data was acquired by AHS - the sole provider of inpatient hospital services in Alberta, Canada. As all hospitalizations and subsequent surveys fall under AHS' umbrella, there are minimal gaps in our data. A final strength lies within the comprehensive survey sampling strategy used by AHS. Successes of this include the high survey response rate (73\% once patient is reached) and the degree of comparability between respondents and other eligible patients who did not take the survey. ${ }^{26}$

There are limitations present in this study. As in the Hachem and colleagues article,$^{15}$ there are factors which may contribute to patient experience and/or readmissions which have not been considered. For example, socioeconomic status and many social determinants of health were not captured. Although household or personal income was not captured, self-reported level of education was included in our adjusted analyses. Previous research has shown that ethnicity/race, another data point which was not available to us, may influence patient experience ${ }^{27,28}$ as well as readmissions. ${ }^{29}$ As surveys did not target specific groups of patients (e.g. with specific diagnoses), it is possible that our results may not apply to particular medical conditions. Due to the cross-sectional 
nature of our study, our results should be also considered as associative and not causal. Given that all surveys were conducted by telephone, we also cannot discount the potential for social desirability bias - where respondents may provide more favorable responses, when compared with those who complete mail-out questionnaires. This has been shown with the HCAHPS survey. ${ }^{30}$ Lastly, although we estimate the effect to be minimal, it is possible a patient could have been readmitted outside of Alberta (e.g. another Canadian province, foreign country), in which case, this encounter would be missing from our dataset.

In conclusion, the present study demonstrates a clear association between patient involvement in their care decisions, receiving written discharge instructions, and subsequent unplanned hospital readmissions up to oneyear post-discharge. Our findings provide objective data which can be easily actioned upon for quality improvement purposes. Perhaps more importantly, our results reinforce that elements of patient reports of their hospital experience are indeed linked with more traditional, objective hospital outcomes.

\section{References}

1. Institute for Healthcare Improvement. The IHI Triple Aim.

http://www.ihi.org/engage/initiatives/tripleaim/pag es/default.aspx. Accessed January 3, 2017.

2. U.S. Department of Health and Human Services. The Affordable Care Act, Section by Section. https://www.hhs.gov/healthcare/about-thelaw/read-the-law/\#. Accessed January 3, 2017.

3. Centers for Medicare and Medicaid Services. Hospital Value-Based Purchasing. https://www.cms.gov/Outreach-andEducation/Medicare-Learning-NetworkMLN/MLNProducts/Downloads/Hospital_VBPur chasing_Fact_Sheet_ICN907664.pdf. Accessed January 7, 2017.

4. Jencks SF, Williams MV, Coleman EA. Rehospitalizations among patients in the medicare fee-for-service program. The New England Journal of Medicine. 2009;360(14):1418-1428.

5. Canadian Institute for Health Information. All-Cause Readmission to Acute Care and Return to the Emergency Department. https://secure.cihi.ca/free_products/Readmission_t O_acutecare_en.pdf. Accessed September 14, 2016.

6. Boult C, Dowd B, McCaffrey D, Boult L, Hernandez $\mathrm{R}$, Krulewitch H. Screening elders for risk of hospital admission. Journal of the American Geriatrics Society. 1993; 41(8):811-817.

7. Krumholz HM, Parent EM, Tu N, Vaccarino V, Wang Y, Radford MJ, et al. Readmission after hospitalization for congestive heart failure among medicare beneficiaries. Archives of Internal Medicine. 1997;157(1):99-104.

8. van Walraven C, Dhalla IA, Bell C, Etchells E, Stiell IG, Zarnke K, et al. Derivation and Validation of an Index to Predict Early Death or Unplanned Readmission after Discharge from Hospital to the Community. Canadian Medical Association Journal. 2010;182(6):551-557.

9. Centers for Medicare and Medicaid Services.

Readmissions Reduction Program.

https://www.cms.gov/medicare/medicare-fee-forservice-payment/acuteinpatientpps/readmissionsreduction-program.html. Accessed January 7, 2017.

10. Boulding W, Glickman SW, Manary MP, Schulman KA, Staelin R. Relationship between patient satisfaction with inpatient care and hospital readmission within 30 days. American Journal of Managed Care. 2011;17(1):41-48.

11. Freedman DA. Ecological Inference and the Ecological Fallacy.

http://web.stanford.edu/class/ed260/freedman549. pdf. Accessed January 3, 2017.

12. Christensen M, Lundh A. Medication review in hospitalised patients to reduce morbidity and mortality. The Cochrane Database of Systematic Reviews. 2016 Feb 20;2:CD008986. doi: 10.1002/14651858.CD008986.pub3.

13. Naylor MD, Brooten DA, Campbell RL, Maislin G, McCauley KM, Schwartz JS. Transitional care of older adults hospitalized with heart failure: a randomized, controlled trial. Journal of the American Geriatric Society. 2004;52(5):675-684.

14. Dhalla IA, O'Brien T, Morra D, Thorpe KE, Wong BM, Mehta R, et al. Effect of a postdischarge virtual ward on readmission or death for high-risk patients: a randomized clinical trial. Journal of the American Medical Association. 2014;312(13):1305-1312.

15. Hachem F, Canar J, Fullam F, Gallan AS, Hohmann $\mathrm{S}$. The relationships between HCAHPS communication and discharge satisfaction items and hospital readmissions. Patient Experience Journal. 2014;1(2).

http:/ / pxjournal.org/cgi/viewcontent.cgi?article $=10$ 22\&context=journal. Accessed September 14, 2016.

16. Jaipaul CK, Rosenthal GE. Do hospitals with lower mortality have higher patient satisfaction? A regional analysis of patients with medical diagnoses. American Journal of Medical Quality. 2003;18(2):59-65.

17. Centers for Medicare and Medicaid Services. HCAHPS Patient-Level Correlations. http://hcahpsonline.org/Files/AprilMay_2016_Summary\%20Analyses_Corrs.pdf. Accessed January 3, 2017.

18. Kemp K, McCormack B, Chan N, Santana MJ, Quan H. Correlation of inpatient experience survey items and domains with overall hospital rating. Journal of Patient Experience. 2015;2(2):29-36. 
19. Centers for Medicare and Medicaid Services. Introduction to HCAHPS Survey Training. http://hcahpsonline.org/Files/A_2016_Introductio n_Training_Slides.pdf. Accessed January 3, 2017.

20. Kemp KA, Chan N, McCormack B, DouglasEngland K. Drivers of inpatient hospital experience using the HCAHPS survey in a Canadian setting. Health Services Research. 2015;50(4):982-997.

21. Canadian Institute for Health Information. Discharge Abstract Database (DAD) Metadata. http://www.cihi.ca/cihi-extportal/internet/en/document/types +of+care/hospi tal+care/acute+care/dad_metadata. Accessed January 7, 2017.

22. Canadian Institute for Health Information. DAD Abstracting Manual, 2012-2013 Edition. 2012. Ottawa, Ontario: Canadian Institute for Health Information.

23. Centers for Medicare and Medicaid Services. A Note About HCAHPS "Boxes".

http:/ /www.hcahpsonline.org/SummaryAnalyses.as px. Accessed January 3, 2017.

24. Committee on Quality of Health Care in America, Institute of Medicine. Crossing the Quality Chasm: A new health system for the $21^{\text {st }}$ century. 2001. Washington, DC: National Academy Press.

25. Gleeson H, Calderon A, Swami V, Deighton J, Wolpert M, Edbrooke-Childs J. Systematic review of approaches to using patient experience data for quality improvement in healthcare settings. $B M J$ Open. 2016;6:e011907. doi:10.1136/bmjopen-2016011907.

26. Kemp KA, Chan N, McCormack B. The Alberta inpatient experience survey: representativeness of sample and initial findings. Survey Practice. 2015;8. http://www.surveypractice.org/index.php/SurveyPr actice/article/view/291/pdf_30. Accessed January 4, 2017.

27. Goldstein E, Elliott MN, Lehrman WG, Hambarsoomian K, Giordano LA. Racial/Ethnic differences in patients' perceptions of inpatient care using the HCAHPS survey. Medical Care Research and Review. 2010;67(1):74-92

28. Morales LS, Elliott MN, Weech-Maldonado R, Spritzer KL, Hays RD. Differences in CAHPS adult survey reports and ratings by race and ethnicity: an analysis of the National CAHPS benchmarking data 1.0. Health Services Research. 2001;36(3):595-617.

29. Oronce CI, Shao H, Shi L. Disparities in 30-day readmissions after total hip arthroplasty. Medical Care. 2015;53(1):924-930.

30. Elliott MN, Zaslavsky AM, Goldstein E, Lehrman W, Hambarsoomian K, Beckett MK, et al. The effects of survey mode, patient mix, and nonresponse on CAHPS survey scores. Health Services Research. 2009;44(3):501-518 
Table 5. Crude and adjusted odds ratios (95\%CI): Unplanned readmissions within 30 days and 43-365 post-discharge

\begin{tabular}{|c|c|c|c|c|c|c|c|c|}
\hline \multirow[b]{2}{*}{ Variable } & \multicolumn{4}{|c|}{ Readmissions within 30 days } & \multicolumn{4}{|c|}{ Readmissions within 43-365 days } \\
\hline & OR & $95 \% \mathrm{CI}$ & $\mathrm{aOR}$ & $95 \% \mathrm{CI}$ & OR & $95 \% \mathrm{CI}$ & $\mathrm{aOR}$ & $95 \% \mathrm{CI}$ \\
\hline \multicolumn{9}{|l|}{ Overall Rating of Care } \\
\hline 9 or 10 (Best Possible) & 1.00 & --- & 1.00 & --- & 1.00 & --- & 1.00 & --- \\
\hline 0 (Worst possible) to 8 & 1.21 & $1.08-1.35$ & $1.16 \mathrm{a}$ & $1.04-1.30$ & 1.09 & $1.02-1.17$ & $1.10 \mathrm{a}$ & $1.02-1.18$ \\
\hline \multicolumn{9}{|l|}{ Patient Involvement in Care Decisions } \\
\hline Yes (as much as desired or somewhat) & 1.00 & --- & 1.00 & --- & 1.00 & --- & 1.00 & --- \\
\hline No (wanted to be more involved) & 1.81 & $1.51-2.17$ & $1.36 \mathrm{~b}$ & $1.12-1.65$ & 1.78 & $1.58-2.00$ & $1.34 \mathrm{~b}$ & $1.17-1.53$ \\
\hline \multicolumn{9}{|l|}{ Received Written Information at Discharge } \\
\hline Yes & 1.00 & --- & 1.00 & --- & 1.00 & --- & 1.00 & --- \\
\hline No & 1.69 & $1.50-1.90$ & $1.18 b$ & $1.04-1.34$ & 1.95 & $1.82-2.10$ & $1.24 b$ & $1.15-1.35$ \\
\hline \multicolumn{9}{|l|}{ Understood Purpose of Taking Medications } \\
\hline Agree & 1.00 & --- & 1.00 & --- & 1.00 & --- & 1.00 & --- \\
\hline Disagree & 1.93 & $1.52-2.46$ & $1.41 \mathrm{~b}$ & $1.09-1.81$ & 1.57 & $1.33-1.85$ & $1.06 \mathrm{~b}$ & $0.88-1.28$ \\
\hline \multicolumn{9}{|l|}{ Understood Responsibility for Own Health } \\
\hline Agree & 1.00 & --- & 1.00 & --- & 1.00 & --- & 1.00 & --- \\
\hline Disagree & 1.76 & $1.43-2.17$ & $1.47 \mathrm{~b}$ & $1.18-1.84$ & 1.23 & $1.06-1.42$ & $1.02 \mathrm{~b}$ & $0.87-1.21$ \\
\hline \multicolumn{9}{|c|}{ Discussed Help Needed when Returning Home } \\
\hline Yes & 1.00 & --- & 1.00 & --- & 1.00 & --- & 1.00 & --- \\
\hline No & 1.33 & $1.15-1.53$ & $1.16 \mathrm{~b}$ & $1.00-1.35$ & 1.22 & $1.12-1.34$ & $1.06 \mathrm{~b}$ & $0.96-1.18$ \\
\hline \multicolumn{9}{|c|}{ Patient Involved AND Received Written Info } \\
\hline Yes to both questions & 1.00 & --- & 1.00 & --- & 1.00 & --- & 1.00 & --- \\
\hline No to both questions & 2.61 & $2.07-3.29$ & $1.53 \mathrm{~b}$ & $1.19-1.96$ & 2.74 & $2.35-3.19$ & $1.54 \mathrm{~b}$ & $1.29-1.83$ \\
\hline
\end{tabular}

a Adjusted for: sex, age group, education level, inpatient hospitalization in previous year, length of hospital stay, self-rating of physical health, self-rating of mental health b Adjusted for all factors in model a + overall rating of care 